\title{
The Influence of Somatosensory Cortex on Climbing Fiber Responses in the Lateral Hemispheres of the Rat Cerebellum after Peripheral Tactile Stimulation
}

\author{
lan E. Brown and James M. Bower \\ Division of Biology, California Institute of Technology, Pasadena, California 91125
}

This report describes the temporal relationship between the latency of responses to peripheral stimulation in primary somatosensory (SI) cerebral cortex and the timing of climbing fiber inputs to the lateral hemispheres of the rat cerebellum. Examined in the tactilely responsive regions of crus Ila in the rat, the results show that $\mathrm{SI}$ influences the timing of both evoked and spontaneous climbing fiber activity in these cerebellar regions without affecting the rate or probability of complex spike discharge. By reversibly blocking SI activity, we demonstrate that the absence of cortical input results in a lengthening of climbing fiber response latency to peripheral stimuli. Similarly, enhancing the cortical input by subthreshold electrical stimulation of SI results in a shortening of climbing fiber response latency. These results provide a new explanation for the tendency of the inferior olive to oscillate at $7-12 \mathrm{~Hz}$ and is consistent with the hypothesis that the inferior olive provides the cerebellum information about the timing of cortical computational cycles. Results are discussed in the context of previous and current hypotheses concerning the physiology and function of the inferior olive/climbing fiber system and are interpreted to provide additional evidence of a role for the cerebellum in the tactile somatosensory system.

Key words: Purkinje cell; somatosensory; complex spike; cerebellar cortex; timing; inferior olive
The climbing fiber system, with its sole origin in the inferior olive (IO) and its mono-axonal "climbing fiber" connection to Purkinje cells (Palay and Chan-Palay, 1974), plays a major role in many hypotheses of cerebellar function (Marr, 1969; Thach et al., 1992; Llinas and Welsh, 1993; Houk et al., 1996). Given the predominance of the view that the cerebellum is primarily a motor control device (Bower, 1997a), most hypotheses for the function of the inferior olive and the climbing fiber system have focused on some link to motor performance. One prominent hypothesis, for example, proposes that climbing fiber discharges specifically signal motor performance errors to cerebellar Purkinje cells, which then change their output to improve motor performance (Kawato and Gomi, 1992). Although this hypothesis does not clearly state how motor error is detected, it is assumed that the inferior olive is the relay for this information. Another proposal links the inferior olive directly to motor learning, suggesting that climbing fiber discharge triggers either the enhancement (Marr, 1969) or depression (Albus, 1971) of coincidently active parallel fibers. In this way it has been proposed that the climbing fiber system "instructs" Purkinje cells as to which of their 150,000 parallel fibers should influence output. A third more recent proposal suggests that climbing fiber firing is responsible for coordinating the timing of movement (Llinas and Welsh, 1993).

Whereas each of these hypotheses is somewhat different, they

Received Dec. 12, 2001; revised May 21, 2002; accepted May 24, 2002.

This research was funded by National Science Foundation Grant 9986772. I.B. was supported by a postdoctoral fellowship from the Medical Research Council of Canada.

Correspondence should be addressed to Ian E. Brown, Center for Neuroscience Studies, Abramsky Hall, Room 109, Queen's University, Kingston, Ontario, K7L 3N6 Canada. E-mail: ianbrown@biomed.queensu.ca.

J. M. Bower's present address: The Research Imaging Center at The University of Texas Health Science Center-San Antonio and the Cajal Neuroscience Research Center at the University of Texas-San Antonio, San Antonio, TX 78284-6240. Copyright (C) 2002 Society for Neuroscience $0270-6474 / 02 / 226819-11 \$ 15.00 / 0$ share in common the idea that the precise timing of climbing fiber discharge is critical to function and related directly to some aspect of movement. In the case of both the motor error and motor learning hypotheses, climbing fiber discharge is assumed to be generated by the detection of some specific motor-related event. In the case of the movement timing hypothesis, the intrinsic properties of the inferior olive itself are assumed to control the timing of climbing fiber activity. In each case, the timing of climbing fiber discharge is linked directly to some particular aspect of movement.

Over the last several years, our laboratory has been investigating the possibility that cerebellar function may be more related to the internal needs of the nervous system than to the types of overt motor behavior proposed in classical hypotheses (Bower, 1997a,b). In particular, we have proposed that the cerebellum may be responsible for coordinating the acquisition of sensory data on which the rest of the nervous system depends. Although this hypothesis has derived primarily from our studies of mossy fiber tactile projections to cerebellar cortex (Bower and Woolston, 1983; Morissette and Bower, 1996), we have recently begun to extend our investigations to include the climbing fiber system (Brown and Bower, 2001). These studies have already demonstrated a strong similarity between the spatial pattern of mossy fiber and climbing fiber tactile projections to tactile regions of the lateral hemispheres in the rat (Brown and Bower, 2001).

In this paper we extend these initial studies to examine the all important question of the control of timing of climbing fiber activity. We have previously hypothesized (Bower, 1997a,b) that the 7-12 Hz oscillatory behavior of the inferior olive might be related directly to the fact that cerebral cortex oscillates at these particular frequencies. In this view, the inferior olive is proposed to be responsible for relaying information about the timing of cerebral cortical computational cycles rather than itself orchestrating anything having to do with movement performance. 
As a first experimental test of this idea, we report here the results of a series of experiments in which timing relations between activity in the somatosensory cortex (SI) and the cerebellum were assessed and manipulated using simultaneous recording techniques. In previous studies of the mossy fiber system we have demonstrated that the pattern of SI projections to the lateral tactile regions of the cerebellum are spatially similar to the pattern of direct trigeminal projections (Bower et al., 1981). Our recent demonstration that climbing fiber projection patterns overlap those of the mossy fiber system (Brown and Bower, 2001) set the stage for the current examination of the relationship between evoked SI cortical and cerebellar complex spike activity. The results presented here provide evidence that SI does, in fact, influence the timing of both evoked and spontaneous climbing fiber activity in these regions of the cerebellum and that it does so without affecting the rate or probability of complex spike firing. This result is consistent with the hypothesis that the inferior olive provides the cerebellum information about the timing of cortical computational cycles.

Preliminary results have been presented previously (Brown and Bower, 2000).

\section{MATERIALS AND METHODS}

Surgery. Results in this study are reported from 14 experiments on 3- to 6-month-old female Sprague Dawley rats. All methods were approved by the California Institute of Technology's Animal Care Committee and conform to National Institutes of Health guidelines. Animals were anesthetized initially with an intraperitoneal injection of a ketamine-xylazine drug cocktail (ketamine, $100 \mathrm{mg} / \mathrm{kg}$; xylazine, $5 \mathrm{mg} / \mathrm{kg}$; acepromozine, $1 \mathrm{mg} / \mathrm{kg}$ ). Supplemental doses ( $20 \%$ of initial dose) were given through an intraperitoneal catheter as needed throughout the experiment to maintain deep anesthesia, as evidenced by the lack of a pinch withdrawal reflex and/or lack of whisking. Body temperature was maintained at $36 \pm 1^{\circ} \mathrm{C}$ with the use of a rectal temperature probe and heating blanket. Heart rate was monitored throughout each experiment. To maintain proper hydration, $0.9 \mathrm{ml}$ of lactated Ringer's solution and $0.1 \mathrm{ml}$ of $50 \%$ dextrose was injected intraperitoneally every $1-2 \mathrm{hr}$. To avoid lung congestion, $0.5 \mathrm{mg} / \mathrm{kg}$ of glycopyrrolate was injected intraperitoneally every $6 \mathrm{hr}$. Animals were killed at the end of the experiment with a $1.0 \mathrm{ml}$ intracardiac injection of Nembutal.

After anesthesia, the head of the animal was immobilized in a custommade head-holder. The muscles covering the occipital region of the skull were removed, as were the muscles covering the temporal region on the right side lateral to bregma. Two screws were drilled into the skull several millimeters caudal to bregma and $2-3 \mathrm{~mm}$ lateral to midline. A surgical staple was placed on cervical vertebrae $\mathrm{C} 2$, and a dental acrylic dam was built encompassing both the screws and the staple. Skin flaps were glued to the side of the dam using cyanoacrylate to prevent leakage. A craniotomy was performed to expose both cerebellar hemispheres as well as the facial region of right primary SI (see Hall and Lindholm (1974), their Fig. 6 for stereotaxic coordinates of this region). The exposed brain was covered with mineral oil, the dam was then bonded to the head holder with more dental acrylic, and the ear and bite bars were removed to allow access to the perioral surfaces. In some experiments, a 3 inch cotton-tipped applicator was glued to the nonglabrous upper and outer parts of the left upper lip and pulled back gently to make the furry buccal pad more accessible (see Fig. 1 for location of furry buccal pad). The dura was cut and pulled back before initiating recording.

Stimulus techniques. Two types of stimuli were used in these experiments to elicit neural responses: electrical stimuli applied to SI and tactile stimuli applied to the perioral regions (Brown and Bower, 2001). Electrical stimuli were constant current, rectangular, monophasic and 0.2 msec in duration and applied through a $0.1 \mathrm{M} \Omega$ tungsten electrode. Preliminary experiments revealed that complex spikes in crus IIa were elicited with the greatest probability when the SI stimulating electrode depth was $2000 \mu \mathrm{m}$, so this depth was used throughout. Tactile stimuli were applied with a computer-controlled probe. Drawings of the rat's face in Figure 1 indicate the perioral regions stimulated during these experiments. The size of the probe tip was $<1 \mathrm{~mm}^{2}$, and the total excursion of the tactile stimuli was $\sim 300 \mu \mathrm{m}$. The stimulus was brief,
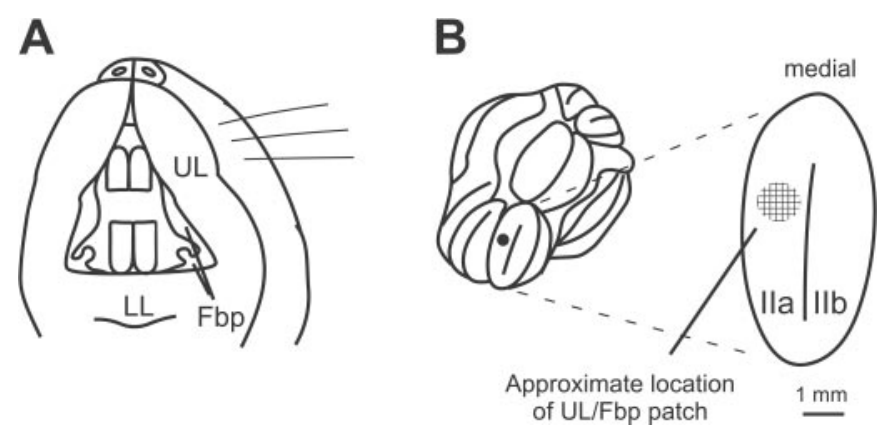

Figure 1. Recording and stimulus locations. $A$, The perioral regions of the rat are shown here. Only the perioral regions were stimulated in these experiments to elicit complex spikes in crus IIa (Brown and Bower, 2001). $B$, Approximate cerebellar recording locations. All experiments except one were from an upper lip $(U L)$ or furry buccal pad $(F b p)$ patch. The one recording from a lower lip $(L L)$ patch was found $\sim 200 \mu \mathrm{m}$ medial to the regions shown here. See Hall and Lindholm (1974), their Figure 6, for location of SI recordings.

completed in $<10 \mathrm{msec}$ (sample stimulus shown in Fig. 2). In all experiments, stimuli of either sort were applied at $2 \mathrm{sec}$ intervals, and peristimulus histograms (PSTHs) were constructed from the resulting spike trains.

Recording techniques. Extracellular recordings were made using tungsten microelectrodes from both SI $(0.1 \mathrm{M} \Omega)$ and from the exposed crown of crus IIa $(2 \mathrm{M} \Omega)$. Care was taken to ensure that the electrodes were placed perpendicular to the relevant brain surfaces before recording. Signals were amplified $1000 \times$ and filtered between $10 \mathrm{~Hz}$ and $5 \mathrm{kHz}$ before being digitally sampled at $10 \mathrm{kHz}$ and stored on a computer. Secondary filtering was accomplished digitally using fourth order doublepass Butterworth filters. Granule cell layer (GCL) field potentials were collected at a depth of 500-600 $\mu \mathrm{m}$ (Bower and Kassel, 1990) and were digitally filtered between 10 and $500 \mathrm{~Hz}$. Complex spikes (CSs) were recorded from the cerebellar molecular layer (100-200 $\mu \mathrm{m}$ depth) and were extracted from the signal using a window discriminator built in Labview 5.1 (National Instruments, Austin, TX) after first digitally filtering the signal between $300 \mathrm{~Hz}$ and $3 \mathrm{kHz}$. CSs were identified as such by their location, their firing rate (typically $<1 \mathrm{~Hz}$ ), and by the complete absence of interspike intervals $<50 \mathrm{msec}$ (Brown and Bower, 2001). Multiunit activity in SI was recorded at the depth at which the strongest response to a tactile stimulus could be evoked (usually at depths of 1000-1200 $\mu \mathrm{m}$ ). SI multiunit data were filtered between $300 \mathrm{~Hz}$ and $3 \mathrm{kHz}$ and then rectified.

To choose recording locations, we identified first an appropriate cerebellar location. The crus IIa electrode was lowered into the location of the usual upper lip/furry buccal pad patch (Fig. 1) down to the GCL and the center of receptive field for that particular cerebellar location was determined using standard manual stimulation and audio classification (Bower and Kassel, 1990). We then mapped SI using the same technique until the location of the corresponding receptive field was found. Because of the relatively high background activity of SI under ketamine-xylazine anesthesia as opposed to under barbiturate anesthesia, SI was difficult to map precisely. For this reason once a tentative SI location was determined, we refined our SI search by stimulating SI with a single electrical pulse at a depth of $2000 \mu \mathrm{m}$ and determined the threshold to elicit a field potential in the GCL of crus IIa (Bower et al., 1981). The SI electrode was moved in a $200 \mu \mathrm{m}$ grid pattern until we found the location with the lowest threshold for eliciting a GCL field potential. GCL field potentials were used for SI mapping instead of CSs because they are quicker to map and because Allen et al. (1974) have shown that stimulation of cerebral cortex elicits mossy fiber and climbing fiber responses in the same Purkinje cells. Once the SI location was chosen, the crus IIa electrode was raised out of the cortex, moved $50-100 \mu \mathrm{m}$ in a mediolateral direction, and lowered to the molecular layer to isolate a CS. Although some patches in crus IIa have been shown to be only $50-100 \mu \mathrm{m}$ in diameter, the upper lip/furry buccal pad patch is usually much larger, often $500-1000 \mu \mathrm{m}$ in diameter (Bower and Kassel, 1990). Confirmation of a connection between SI and the new adjacent crus IIa location was then made by stimulating in SI with a 3 pulse train at $500 \mathrm{~Hz}$ with $150 \mu \mathrm{A}$ (Allen et al., 1974) and observing the CS response.

Lidocaine injection in SI. In one series of experiments we injected 300 


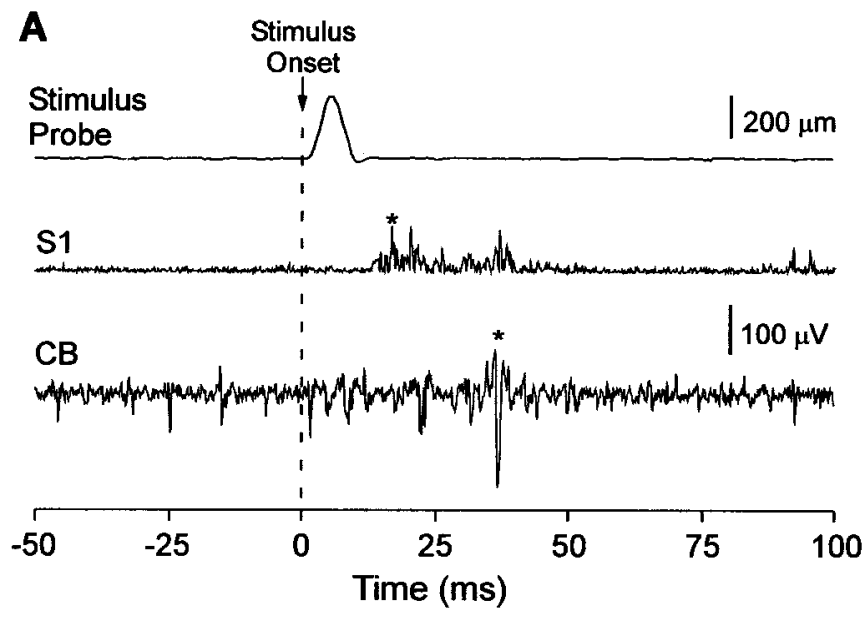

B

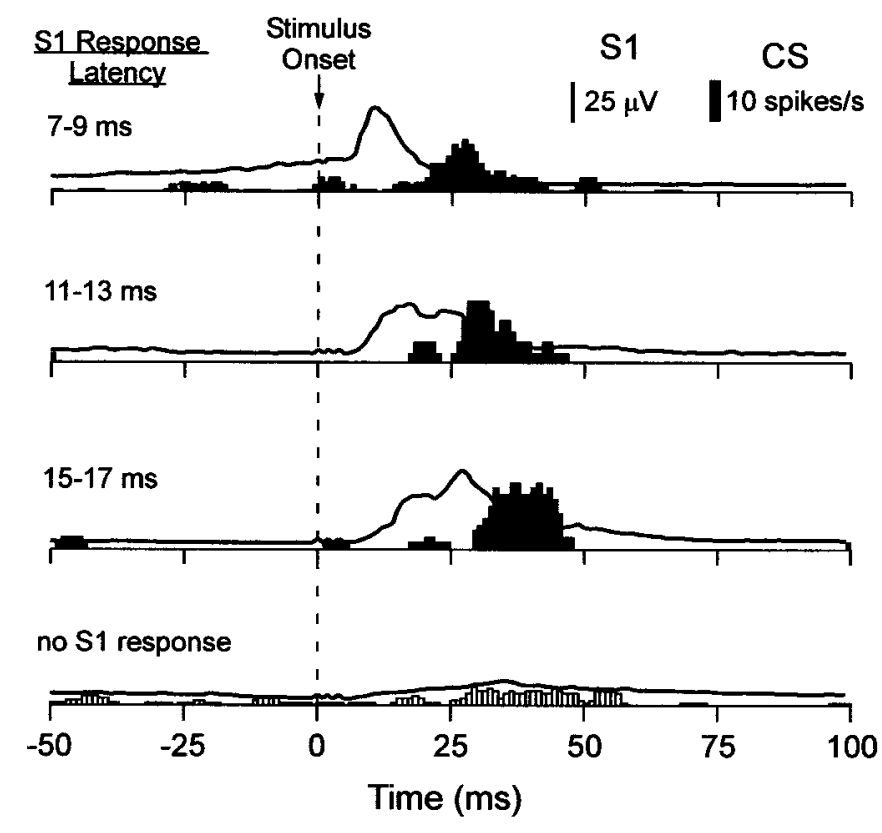

Figure 2. Correlations between SI multiunit burst latencies and CS latencies: sample data. The data shown were collected from one paired recording. $A$, Sample data from one trial. The three traces show the tactile stimulus probe excursion, the SI-rectified, multiunit activity, and cerebellar activity, respectively. The time at which the SI multiunit activity crossed the $50 \mu \mathrm{V}$ threshold and the time of a CS in the cerebellar trace are each indicated with an asterisk. The voltage scale is the same for both the SI and cerebellar traces. $B$, Data trials were sorted by SI response latency into six data sets ( $2 \mathrm{msec}$ bins). Trials were considered to have an SI burst if the SI rectified, multiunit activity crossed a threshold of $50 \mu \mathrm{V}$. These data are indicated with a filled bar. A seventh data set was constructed from those trials in which no SI response was detected, indicated with open bars in this figure. PSTHs were constructed from the CS spike trains for each data set. The mean, rectified multiunit SI activity was also calculated for each data set. PSTHs were calculated using $1 \mathrm{msec}$ bins followed by filtering with a $5 \mathrm{msec}$ rectangular moving average. PSTHs were normalized to indicate the instantaneous firing frequency. For clarity, data from only four of the seven data sets are shown. Calibration is the same for all data sets.

$\mathrm{nl}$ of $2 \%$ lidocaine into SI to determine the effect on complex spikes elicited by a tactile stimulus. The apparatus used for injection is described by Malpeli (1999).

Preliminary experiments revealed that field potentials in the granule cell layer were blocked most effectively when the lidocaine injection depth was $2000 \mu \mathrm{m}$. This finding, coupled with the above finding that $2000 \mu \mathrm{m}$ was the optimal depth for eliciting a complex spike in response to electrical stimulation, led us to use an injection depth of $2000 \mu \mathrm{m}$. Lidocaine injections in SI have been shown previously to last $\sim 10 \mathrm{~min}$ when used to block GCL responses in SI (Morissette and Bower, 1996), as expected considering the known actions of lidocaine (Malpeli, 1999). The duration of the injection itself was typically 15-30 sec.

\section{RESULTS}

\section{Correlations between responses in somatosensory cortex and climbing fiber discharges}

Our first series of experiments were designed to look for a relationship between the latency of SI multiunit responses and the latency of CS responses recorded in the cerebellum. To do so, simultaneous recordings were made from SI cortex and the cerebellum while applying a $0.5 \mathrm{~Hz}$ tactile stimulus to the center of the previously determined appropriate receptive field (see Materials and Methods). A sample trial from one experiment is shown in Figure $2 A$ showing the relationship between the tactile stimulus, the SI multiunit burst response, and a CS response. The topmost trace shows the onset and shape of the tactile stimulus used in all experiments. The SI recording is shown in the second trace, with the asterisk indicating the time at which the rectified SI multiunit activity crossed a threshold of $50 \mu \mathrm{V}$ (see Materials and Methods). This criterion was used in all experiments to define the onset of an SI multiunit burst. The last trace in Figure $2 A$ is a simultaneously obtained recording from the cerebellum with the asterisk indicating a climbing fiber discharge.

The results shown in Figure $2 B$ examine the specific relationship between the evoked SI bursts and complex spike discharges in the cerebellum for a single paired recording. Trials were sorted into six groups based on S1 burst latency if the latencies were between 7 and 19 msec. All other trials were grouped together and classified as having no SI burst response to separate out spontaneous SI activity. Climbing fiber PSTHs for three of the six SI response groups are shown in Figure $2 B$ with filled bars, along the one data group for which there was no detectable SI response (open bars). Each PSTH was normalized to indicate the instantaneous firing frequency. Also plotted on these graphs is the mean, rectified multiunit SI activity (continuous line). These data, from a single paired recording, show that the response latency of the CS is correlated positively with the SI response latency.

Because the range and distribution of SI burst latencies was identical for all experiments, trials from all experiments were pooled for the subsequent analyses (the composite SI latency histogram is shown in Fig. $3 A$ ). Trials were sorted as described for the single experiment above into six groups based on S1 burst latency if the latencies were between 7 and $19 \mathrm{msec}$ ( filled bars in Fig. $3 A$ ). All other trials were grouped together and classified as having no SI burst response to separate out spontaneous SI activity (open bars in Fig. $3 A$ ). The composite climbing fiber PSTHs for three of the six SI response groups are shown in Figure $3 B$ (filled bars), along the one data group for which there was no detectable SI response (open bars). Also plotted on these graphs is the mean, rectified multiunit SI activity (continuous line).

Examination of the combined data in Figure $3 B$ again shows clearly that when the data from multiple experiments are pooled together, CS response latency is correlated positively with the SI response latency. For example, when the SI response occurred from 7-9 msec after a tactile stimulus, the latency of the histogram peak for the corresponding CS in the cerebellum was $27 \pm$ 

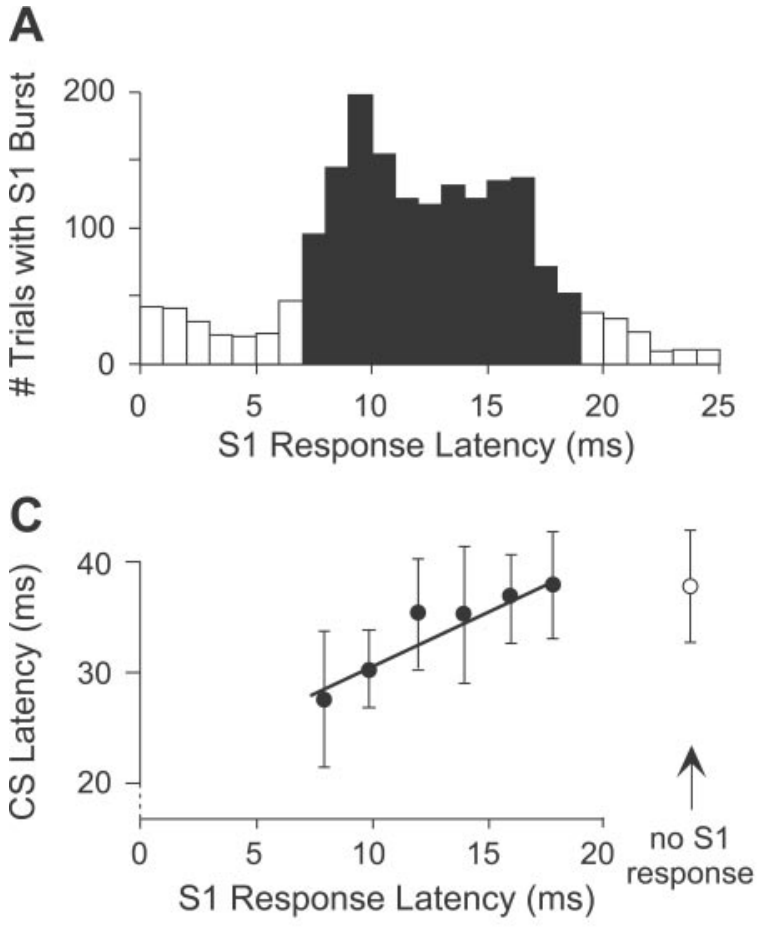

D

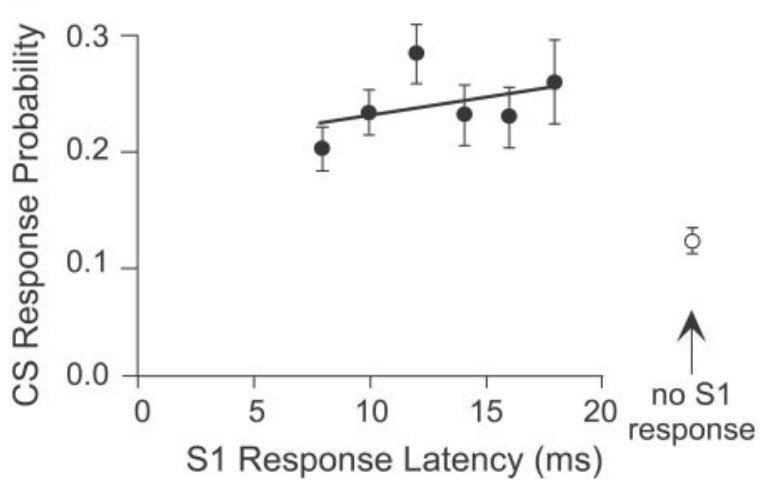

B

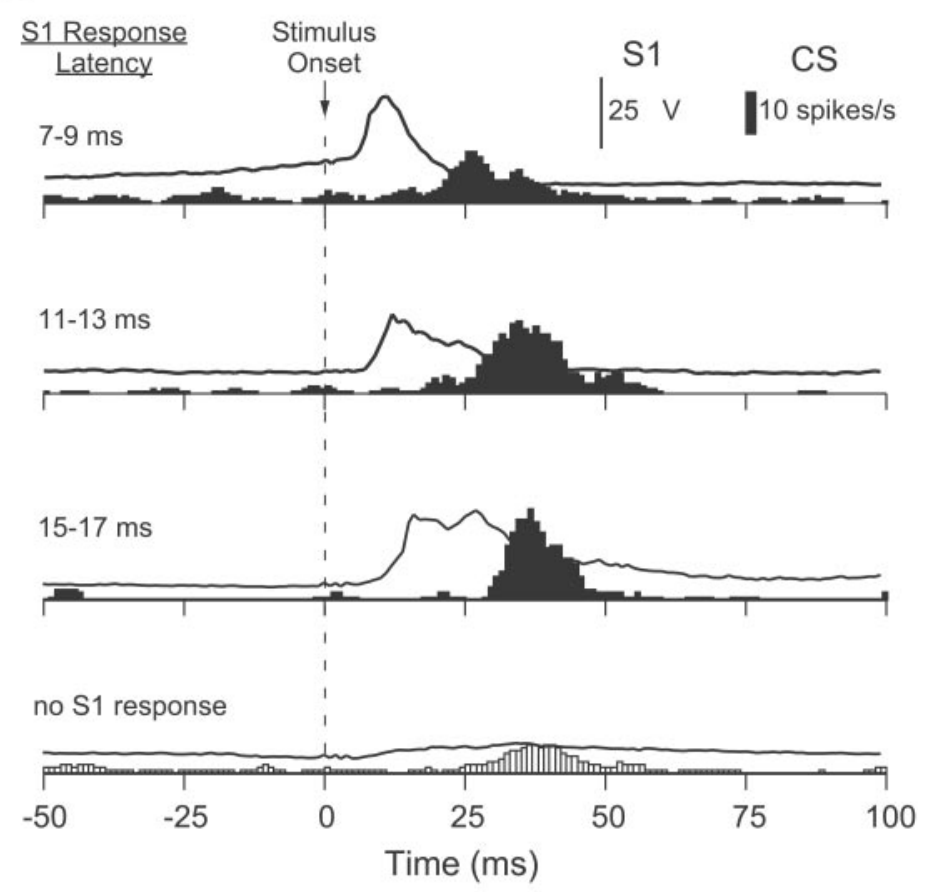

$\mathbf{E}$

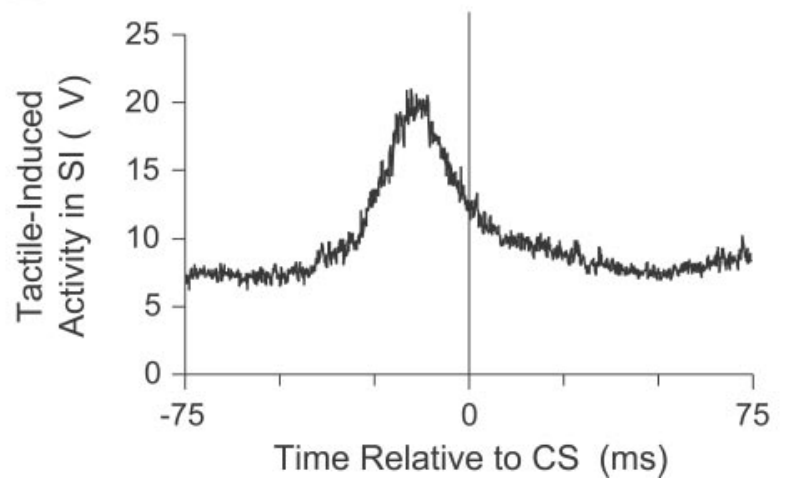

Figure 3. Correlations between SI multiunit burst latencies and CS latencies: summary data. The data shown were collected from five paired recordings in four rats. Trials were considered to have an SI burst if the SI-rectified, multiunit activity crossed a threshold of $50 \mu \mathrm{V}$, as shown in Figure 2 . These data are indicated with filled circles and filled bars in $A-D$, whereas data in which no SI response was detected are indicated with open circles and open bars. A, Histogram of SI burst latencies from all cells combined (1 msec bins). Based on this histogram, data trials were classified as having an SI response if the latency of threshold crossing was between 7 and $19 \mathrm{msec}$ ( filled bars); a total of 1849 of 2700 trials were thus classified as having an SI response. $B$, Data trials were sorted by SI response latency into six data sets (2 msec bins). A seventh data set was constructed from those trials in which no SI response was detected. PSTHs were constructed from the CS spike trains for each data set. The mean, rectified multiunit SI activity was also calculated for each data set. PSTHs were calculated using $1 \mathrm{msec}$ bins followed by filtering with a $5 \mathrm{msec}$ rectangular moving average. PSTHs were normalized to indicate the instantaneous firing frequency. For clarity, data from only four of the seven data sets are shown. Calibration is the same for all data sets. $C$, CS latency (mean $\pm \mathrm{SD}$ ) for each of the seven data sets is plotted as a function of mean SI response latency ( filled circles) or "no SI burst" (open circle). CS latencies were determined by least-squares fitting of a Gaussian to each PSTH with the peak of the Gaussian used as a measure of the CS latency. A linear least-squares best-fit to the SI response data is shown on the plot $(y=1.02 x+19.8 ; r=0.95 ; p<0.01)$. D, CS response probability $( \pm \mathrm{SE})$ at $15-60 \mathrm{msec}$ latency is plotted as a function of SI response latency. A linear least-squares best fit to the data with an SI response is shown on the plot $(y=0.003 x+0.20 ; r=0.42 ; p>0.2)$. All CS response probabilities associated with an SI response were significantly greater than the CS response probability in the absence of an SI response $(t$ test, $p<0.005)$. E. Cross-correlogram of evoked CS spike trains with rectified SI multiunit activity. Peak SI activity leads CSs by $13 \mathrm{msec}$. The full-width-half-maximum is $22 \mathrm{msec}$. (Note: the reason that the latency differences in parts $C$ and $E$ are different, at 20 and $13 \mathrm{msec}$, respectively, is because in the former the latency difference was determined using the start of an SI burst, whereas in the latter the difference was determined using the peak of the SI burst.)

$6 \mathrm{msec}$ (mean $\pm \mathrm{SD})$. In contrast, when the latency of the SI tactile response was from $15-17 \mathrm{msec}$, the latency of CS histogram peak occurred at $37 \pm 4 \mathrm{msec}$. Figure $3 B$ shows that intermediate values of SI response latency correlate with intermediate CS latency values. This relationship is quantified in Figure $3 C$, which shows a near-unity slope relationship between the latency of the SI and climbing fiber responses. Interestingly, in those trials in which SI does not respond according to the above criteria (bottom traces in Fig. $3 B$ ), the latency histogram for the CS closely resembles the histogram corresponding to the longest SI latency delays (both PSTH peaks are at $38 \pm 5 \mathrm{msec}$ ). In Figure $3 E$ the temporal relationship between these events is 
plotted on a trial by trial basis in the form of a cross-correlogram. The results show clearly a significant temporal relationship between SI and CS activity, with a peak timed at $13 \mathrm{msec}$, SI leading.

In Figure $3 D$ we plot the relationship between SI response latency and $\mathrm{CS}$ response probability. In contrast to what was observed for CS latency, CS response probability was not statistically correlated with the latency of an SI response. There was, however, a statistically significant relationship between the probability of a CS response and the occurrence of an SI response (see figure legend). This latter relationship was examined through other experimental means described subsequently and found to be merely correlative, not causal.

\section{The effects of injecting lidocaine into somatosensory cortex on climbing fiber responses}

In the data just described we showed statistical correlations between the latency of SI and CS responses and also between the probability of SI and CS responses. To further examine the effect of SI on CS activity, we conducted a second series of experiments in which $300 \mathrm{nl}$ of $2 \%$ lidocaine injected at a depth of $2000 \mu \mathrm{m}$ to locally anesthetize SI. Previous experiments in our laboratory have shown that such injections reversibly block SI influences on cerebellar mossy fiber activity (Morissette and Bower, 1996).

Sample data from one lidocaine injection experiment are shown in the dot raster of Figure $4 A$. As summarized in the PSTHs on the right, the timing of CS responses in the cerebellum were significantly different during a $10 \mathrm{~min}$ period after lidocaine injection when compared with controls. The duration of this effect was similar to the duration observed in our previous studies using lidocaine (Morissette and Bower, 1996). The interesting point here, however, was that locally anesthetizing SI resulted in a prolongation of the CS response latencies. In fact, the induced delays in CS responses were essentially identical to the delays seen when stimuli failed to elicit an SI response as shown in the first series of experiments ( $40 \pm 5$ vs $38 \pm 5 \mathrm{msec}$, respectively; mean $\pm \mathrm{SD})$. On average, injection of lidocaine into SI delayed the peak of the CS latency distribution by $8 \pm 3$ msec (mean \pm $\mathrm{SD}$ ). These data are summarized for four experiments in Figure $4 B$. As shown in Figure 4, $C$ and $D$, this change in latency took place without affecting either the level of spontaneous CS activity or the CS response probability (Fig. 4C,D; see figure legends for statistical summaries). Thus the relationship between SI and CS response probabilities observed under control conditions appears to have been correlative, not causal.

\section{Simultaneous tactile stimulation and electrical stimulation of somatosensory cortex}

From the results just presented it would appear as though removal of the influence of somatosensory cortex has the effect of prolonging the latency of tactilely evoked CS responses in cerebellar cortex, but without affecting their probability. In a third series of experiments we sought to determine whether enhanced activity in SI cortex would have the effect of reducing CS latencies, again, without affecting CS response probability. To examine this question, we delivered an electrical shock stimulus to SI cortex and a peripheral tactile stimulus at the same time. It is important to note that the intensity of the electrical stimulus presented in SI was intentionally set to be subthreshold for evoking a CS response by itself (middle histogram on the right of Fig. 5B).

The results shown in Figure 5 demonstrate that coincident activation of the periphery and SI cortex do, in fact, reduce the latency of the CS responses without affecting CS response probability. The statistically significant shortening of the response in the presence of SI electrical stimulation is quantified in Figure $5 B$. Sample data from one experiment are shown in Figure $5 A$. As shown in the histograms on the right of Figure $5 A$, coincident electrical SI and peripheral tactile stimulation (top histogram) resulted in a peak $C S$ latency that was earlier by $8 \pm 5 \mathrm{msec}$ (mean $\pm \mathrm{SD}$ ) when compared with tactile stimulation alone (bottom histogram). This result is summarized for data pooled over five experiments in Figure $5 B$.

Once again, in this paradigm of coincident tactile and electrical stimuli, the changes in CS latency were effected without any change in either the CS spontaneous activity or the CS response probability (Fig. 5C,D; see figure legends for statistical summaries). This latter observation confirms that the relationship between SI and CS response probabilities observed under control conditions in Figure $3 D$ appears to have been merely correlative, not causal.

As a side note, although we decreased the effective SI latency in this paradigm from a tactile-evoked $7-19 \mathrm{msec}$ to an electrically induced $0 \mathrm{msec}$, it is important to note that we should not have expected necessarily a similar 7-19 msec decrease in CS latency. If only the onset latency of the SI response was important for CS modulation, then we would expect a 7-19 msec decrease in CS latency. However, it is likely that at least some portion of the 10-30 msec duration SI response beyond the initial onset is responsible for CS modulation. As a simplistic example, consider the possibility in which the mean latency of the SI response is the critical factor modulating CS latency. For a tactile-evoked 10 msec duration SI response with an onset of $7 \mathrm{msec}$, the mean SI response latency would be $12 \mathrm{msec}$. If a $2 \mathrm{msec}$ SI burst of equivalent amplitude was artificially added via electrical stimulation at $t=0 \mathrm{msec}$ to this same response, then the mean SI latency would become $\sim 10 \mathrm{msec}$, a decrease of only $2 \mathrm{msec}$. This decrease in the mean SI latency of $2 \mathrm{msec}$ is much less than the decrease of $7 \mathrm{msec}$ of SI onset latency. Clearly the real relationship between SI responses and CS modulation is somewhere between these two extreme possibilities. Thus, when we stimulate SI electrically, although the onset of cortical input to the IO is reduced by $7-19 \mathrm{msec}$, because the rest of the tactile-evoked SI response is not reduced in latency we should not expect necessarily the CS latency to shorten by $7-19 \mathrm{msec}$ as well.

\section{The influence of spontaneous activities on SI and CS responses}

The data presented up to this point indicate clearly that there is some relationship between the timing of SI and CS responses induced by tactile stimuli. When SI response latencies are short, so are CS latencies; when SI responses are longer, so are those of the CS. At the same time, however, it is clear that the probability of a CS response is not dependent directly on either the latency or the occurrence of a response in SI. CS tactile responses are still generated when SI cortex either does not respond to the stimulus or is locally anesthetized, although in both cases the CS response latencies are unusually long. When these data are combined with the evidence that enhanced SI activity results in a decrease in CS response latency, it would seem reasonable to propose that SI has a facilitatory effect on IO responsiveness.

To better understand the nature of this influence, we performed several additional analyses of our data. First, we were interested in determining what, if any, relationship might exist between spontaneous SI bursts and spontaneous CS activity. 


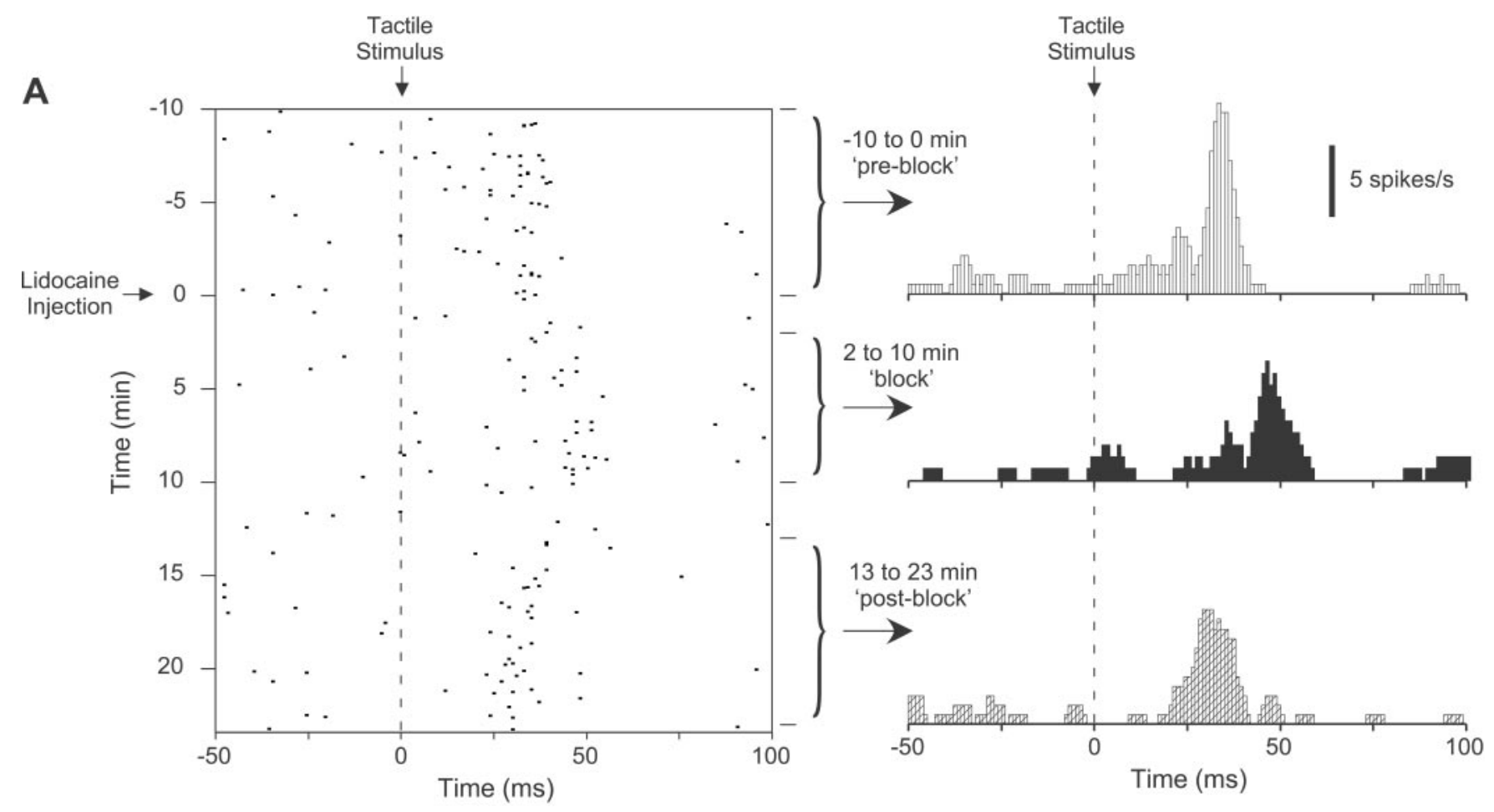

B

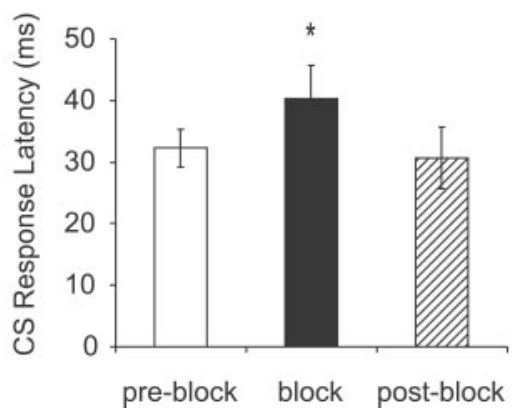

C

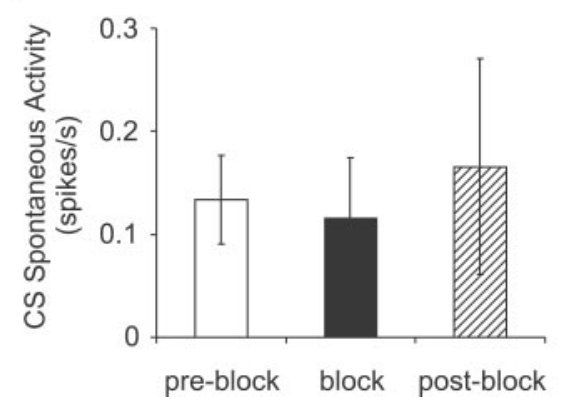

D

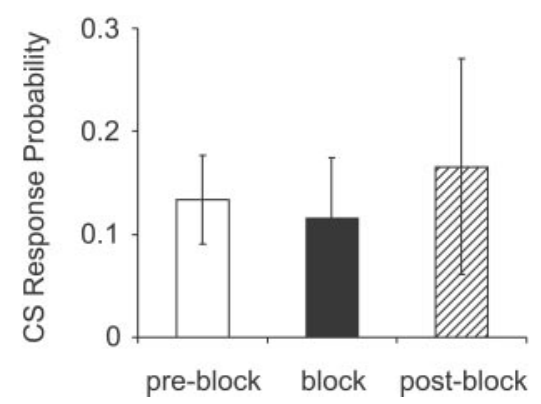

Figure 4. Effects of $300 \mathrm{nl}$ of $2 \%$ lidocaine injected into SI at a depth of $2000 \mu \mathrm{m}$. Data were collected continuously from before the injection of lidocaine ("pre-block", indicated by open bars), immediately after the injection ("block", indicated by filled bars), and for an extended period after the injection ("post-block", indicated by hatched bars). Data were collected from four experiments. In one experiment the block lasted significantly longer than usual, and so the data from 23-33 min after injection were used for post-block analysis instead of the usual 13-23 min. A, Sample 1000-trial raster of CSs and corresponding PSTHs from one experiment. The onset of the tactile stimulus is indicated with dashed lines (see Fig. 2 for a sample stimulus trace). PSTHs were calculated using $1 \mathrm{msec}$ bins followed by filtering with a $5 \mathrm{msec}$ rectangular moving average. $B$, CS latencies (mean \pm SD). CS latencies were calculated for each experiment by taking the peak value of a Gaussian least-squares fit to each PSTH. Mean CS latency during the lidocaine block was significantly greater than the mean latency before block (40 \pm 5 and $32 \pm 3$ msec, respectively; paired $t$ test, $p<0.02)$. The post-block latency of $31 \pm 5 \mathrm{msec}$ was not significantly different from the pre-block latency $(p>0.3)$. Note that the mean latency during block was not significantly different from the mean latency observed in the absence of an SI response in Figure 3 ( $40 \pm 5 \mathrm{vs} 38 \pm 5$ ). $C$, CS spontaneous activity for the 50 msec before stimuli onset $($ mean $\pm \mathrm{SD})$. The mean rates of spontaneous activity for the block trials and post-block trials were not significantly different compared to the pre-block trials (paired $t$ tests; $p>0.2$ ). $D$, CS response probability at 15-60 msec latency (mean \pm SD). Mean probabilities during the block and post-block were not significantly different from pre-block (response probabilities were $0.14 \pm 0.04,0.12 \pm 0.06$, and $0.17 \pm 0.11$ for pre-block, block, and post-block, respectively; paired $t$ tests, $p>0.15$ ).

With light anesthesia, both SI and the cerebellum become quite spontaneously active. An examination of spontaneous activity removes possible confounding effects of stimulus presentation.

The data from our analysis of the relationships between spontaneous SI and CS behavior is shown in Figure 6. First we examined general facilitatory influences of SI on the IO by comparing the level of spontaneous multiunit activity in SI to the rate of spontaneous CS activity in cerebellum. Data for this analysis were collected from the same five paired recordings reported in Figure 3. As expected, the higher the rate of spontaneous neural activity in SI, the greater the rate of spontaneously occurring CSs (Fig. 6A). To determine whether this effect might be caused by the general arousal of both regions by some other system, for example, rather than some specific influence of SI activity on the IO, we performed a cross-correlation between spontaneous SI activity and CS responses. The results shown in Figure $6 B$ show that there is a correlation between both types of spontaneous activity with SI activity leading that of the CS, albeit with less of a lead than was observed previously for the tactile-evoked responses. From this data we conclude that even in the case of 
A
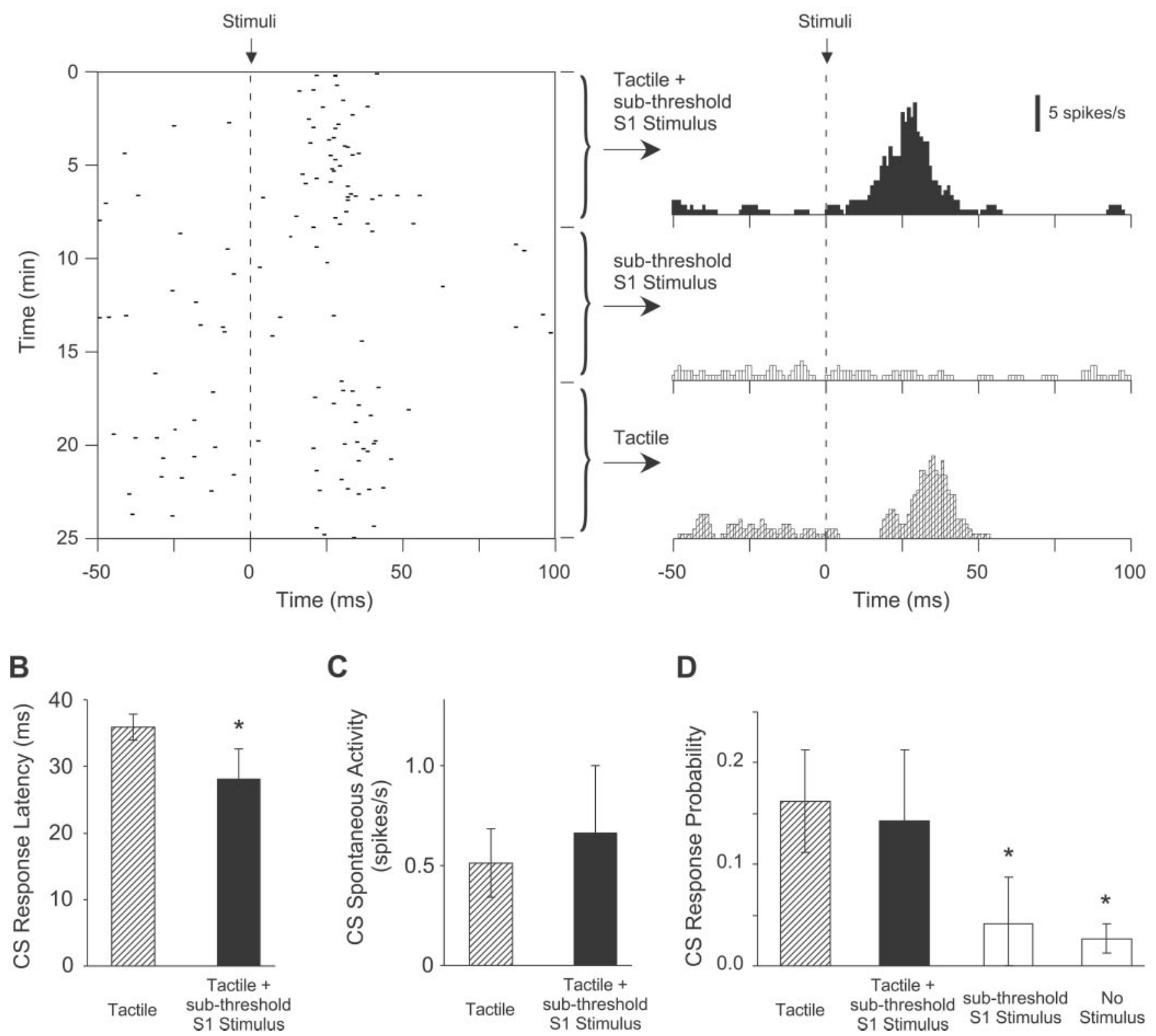

Figure 5. Interaction between tactile stimulus and subthreshold SI electrical stimulus. Data are shown from five experiments. $A$, Sample 900 trial raster of CSs and corresponding PSTHs from one experiment. PSTHs were calculated using $1 \mathrm{msec}$ bins followed by filtering with a 5 msec rectangular moving average. Data were collected continuously; stimuli were changed quickly between trials as necessary. All stimuli were applied at $t=0$, as indicated by the dashed lines. B, CS latencies (mean $\pm \mathrm{SD}$ ). CS latencies were calculated for each experiment by taking the peak value of a Gaussian least-squares fit to each PSTH. Tactile plus SI stimulus-evoked responses were significantly earlier than tactile stimulus alone-evoked responses as indicated by the asterisk (28 \pm 5 and $36 \pm 2 \mathrm{msec}$, respectively; paired $t$ test, $p<0.01)$. C, CS spontaneous activity for the 50 msec before stimuli onset (mean \pm SD). The mean rate of spontaneous activity for the tactile + SI stimulus trials was not significantly different compared with the tactile stimulus alone trials (paired $t$ test; $p>0.2$ ). $D$, CS response probability at $15-60 \mathrm{msec}$ latency (mean $\pm \mathrm{SD}$ ). Tactile plus SI stimulus-evoked response probability was not significantly different from tactile alone-evoked response probability $(0.14 \pm 0.07$ and $0.16 \pm 0.05$, respectively; paired $t$ test, $p>0.1)$. SI stimulus alone response probability was not significantly different from what would be expected in the absence of a stimulus based on spontaneous activity rates $(0.04 \pm$ 0.05 and $0.03 \pm 0.01$, respectively; paired $t$ test, $p>0.2$ ). However, both the SI stimulus alone response probability and the no-stimulus response probability were significantly less than the tactile stimulus alone response probability, as indicated by the asterisk (paired $t$ tests, $p<0.01$ ).

activity occurring in the absence of any overt peripheral stimulus, SI can have a facilitatory effect on the IO.

\section{Spontaneous SI activity}

In this analysis it is important to note once again that SI cannot be said to be responsible for driving IO activity. In fact, as shown in Figure $6 C$, the probability of occurrence of a CS tactile response is statistically independent of the level of SI spontaneous activity immediately before the stimulus, in addition to being independent of SI response latency (Fig. 3D) or SI response probability (Figs. $4 D, 5 D$ ). In this sense overall activity and the probability of response in SI and the IO appear to be independently regulated, but SI activity nevertheless influences the timing of IO-CS responses when they occur.

A final examination of the possible influence on CS latency by 
Figure 6. Effects of spontaneous activities. $A$, Spontaneous CS activity (mean $\pm \mathrm{SD}$ ) is plotted as a function of mean spontaneous SI multiunit activity. Trials were sorted based on spontaneous SI activity into eight groups of approximately equal numbers of trials. $B$, Crosscorrelogram of CS spike trains with rectified SI multiunit activity for spontaneous activity. Dashed lines indicate the temporal location of the cross-correlogram peak for tactile-induced responses as plotted previously in Figure $3 E$ (not to scale vertically). The data plotted here are derived from the same five paired SI-cerebellar recordings first described for Figure 3. Spontaneous data were collected during the 200 msec before a tactile stimulus. Peak SI activity leads CSs by $7 \mathrm{msec}$ for the spontaneous activity cross-correlogram versus $13 \mathrm{msec}$ for tactile stimulus-induced case. The full-width halfmaxima of the peaks is $42 \mathrm{msec}$. $C$, The effect of SI spontaneous activity on CS response probability. SI spontaneous activity for the $50 \mathrm{msec}$ before a tactile stimulus is plotted versus the probability of a CS response with $15-60 \mathrm{msec}$ latency. Data were sorted by SI spontaneous activity into eight groups, as described in $A$. A linear least-squares best-fit to the data are shown on the plot $(r=0.00 ; p>0.5) . D$, The effect of spontaneous SI activity on CS latency is plotted for those trials in which there was no SI response to avoid the influence of SI latency on this analysis. Data were sorted into four groups of approximately equal numbers of trials based on the spontaneous SI activity for the $50 \mathrm{msec}$ before a stimulus. No statistically significant relationship was observed $(r=-0.03 ; p>0.5)$.
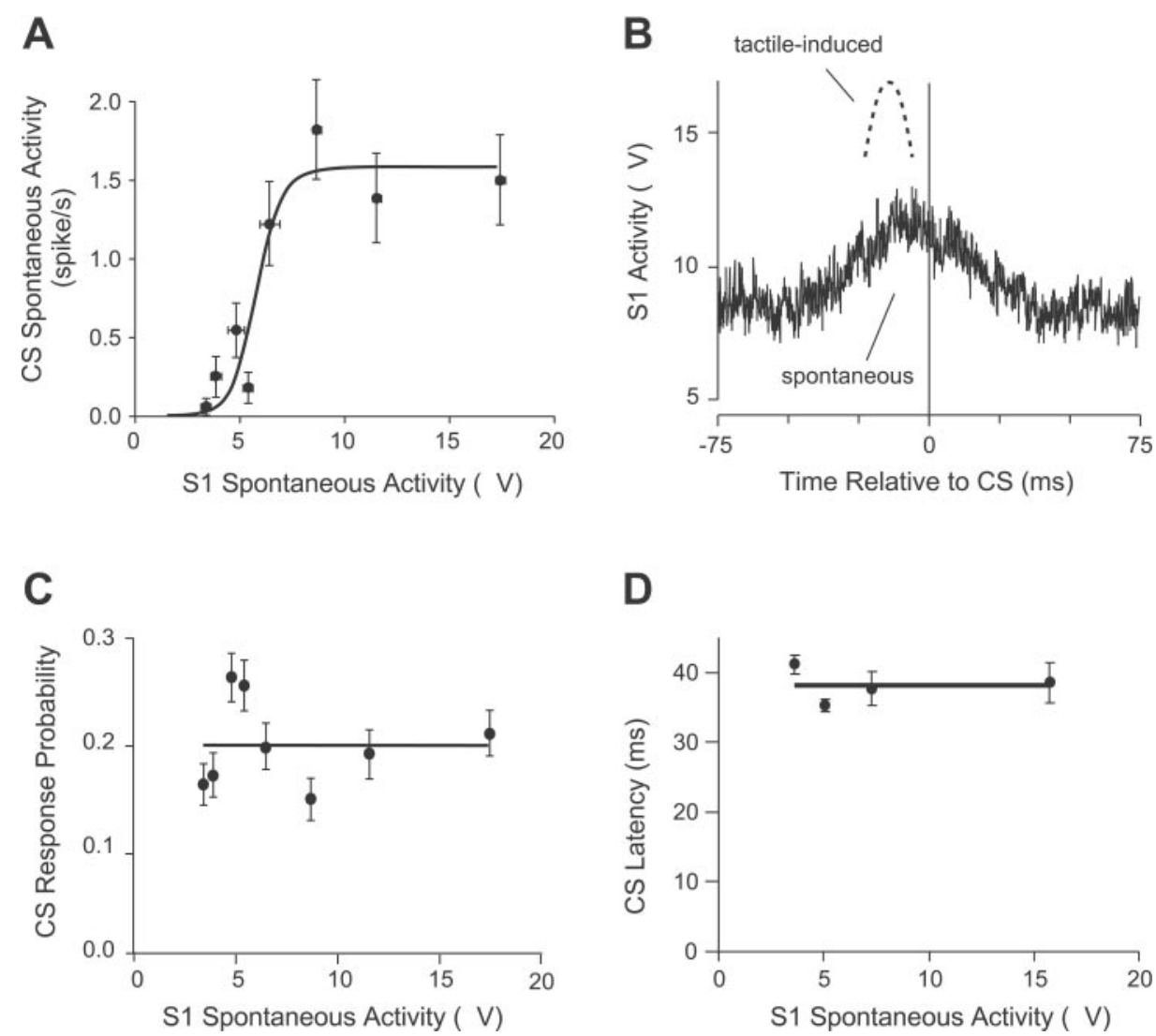

both spontaneous CS and SI activities is warranted because of the data presented in Figure $3 B$ that suggest possible correlations between these phenomena. When the data were sorted by spontaneous CS activity for the $50 \mathrm{msec}$ before a stimulus, the mean CS latency was similar for those trials with and without a spontaneous CS $(36 \pm 3$ and $34 \pm 6$ msec respectively; mean $\pm \mathrm{SD}$, $t=1.22, p>0.2$; data not plotted). We next sorted the trials by spontaneous SI activity during the $50 \mathrm{msec}$ before the tactile stimulus. To avoid any possible influences of SI latency, which is correlated with both spontaneous SI activity and CS latency (Fig. $3 B$ ), we examined only those trials in which there was no SI response. Summary data are plotted in Figure 6D, showing that there was no correlation between spontaneous SI activity and CS latency when there was no SI response. Thus, spontaneous SI activity does not have any direct effect on CS response latency; the apparent correlations observed in Figures 2 and 3 are instead attributable presumably to spontaneous SI activity influencing SI responses, which, as shown above, influence CS response latencies.

\section{DISCUSSION}

The primary conclusion of this study is that SI appears to influence the timing of CS activity recorded in the cerebellum and that it does so without influencing the probability of CS activity. This SI influence is seen when responses are evoked by a peripheral stimulus as well as during spontaneous activity. In the following sections we consider the role that SI appears to play in modulating CS responses, by describing first the circuitry likely to underlie these influences and then the implications of these results for functional relationships between SI and the cerebellum. We also consider the larger implications of our results for hypotheses of the inferior olivary climbing fiber projections in cerebellar function.

\section{Trigeminal-cerebellar pathways}

The regions of the rat's face stimulated in these experiments are innervated by primary trigeminal afferents converging on the trigeminal nuclear complex (Waite, 1984). As demonstrated by Huerta et al. (1983), only two trigeminal subnuclei, principalis and the dorsal part of interpolaris, provide direct mossy fiber projections to the crus II region of the cerebellum. We have also demonstrated the presence of an indirect mossy fiber input to these same cerebellar locations that involves cerebral cortex (Bower et al., 1981; Morissette and Bower, 1996). This loop also originates in the trigeminal nucleus, whose subdivisions all project to the thalamus (Fukushima and Kerr, 1979; Bruce et al., 1987; Williams et al., 1994). The thalamus, of course, projects to SI (Koralek et al., 1988), which in turn influences the cerebellum through the mossy fiber projections of the pontine nuclei (Leergaard et al., 2000).

Unfortunately, less is known about trigeminal-olivary projections. It has been shown that a trigeminal-olivary-crus II projection arises from the ventral aspect of nucleus interpolaris (Huerta et al., 1983), whereas nucleus principalis does not appear to project to the inferior olive (Watson and Switzer, 1978; Swenson and Castro, 1983a,b). Thus, there is apparently no overlap between direct trigeminal-olivary and direct trigeminal-cerebellar projections. It is also as yet unclear by what pathway SI influences the inferior olive. It is known that there are no direct projections from SI to the IO (Sousa-Pinto and Brodal, 1969) and also, at least in the cat, that SI effects on the olive are not mediated through an indirect projection through motor cortex 
(Rowe, 1977). It is known, however, that large regions of the cerebral cortex project to the red nucleus (Leichnetz et al., 1984; Saint-Cyr, 1987) and that the red nucleus influences the inferior olive (Weiss et al., 1990; McCurdy et al., 1992; Horn et al., 1998). Additional studies clearly will be necessary to identify the pathway or pathways mediating the physiological influences reported here.

\section{Previous studies of the influence of somatosensory cortex on the inferior olive}

Very few previous studies of cortical influence on the inferior olive have focused on SI. Previous observations that are relevant and consistent with our results include the demonstration that CSs can be evoked by SI stimulation (Miller et al., 1969; Miles and Wiesendanger, 1975) and that there is convergence onto inferior olive neurons from SI and spinal pathways (Miller et al., 1969). Given that the SI-IO connection is indirect, whether this convergence occurs at the level of the inferior olive or at some intermediate connection between SI/spinal cord and the inferior olive is, as yet, unknown.

To date, almost no studies have looked specifically at the temporal interaction between cerebral cortical and IO activities, despite the fact that many hypotheses of cerebellar function postulate a substantial role for cerebral cortex in guiding cerebellar processing (Houk and Wise, 1995). It is interesting to note, however, that in preparations in which cortex has been suppressed with barbiturate anesthesia the effect is to shorten CS latency (Gellman et al., 1983, 1985; Robertson, 1987; Atkins and Apps, 1997), an outcome that is the opposite of that observed here. It is not clear at this juncture whether or not the differences are caused by global cortical inactivation versus local SI inactivation and/or long-term suppression of cortical efferents versus short-term suppression.

\section{Physiological interactions between somatosensory cortex and the inferior olive}

Although it is not clear by what pathway the influence is felt, our results suggest that SI is providing an important modulating influence on the timing of activation of inferior olivary neurons. We base the conclusion that the influence is modulatory on the fact that SI activity appears to change the timing of CS responses without affecting the actual probability of a CS response. Furthermore, when the data were sorted by SI latency, the peak of the CS latency histogram ranged continuously from 27 to $38 \mathrm{msec}$ (Fig. 3B). Thus, it appears unlikely that the inferior olive is responding differentially to two different sources of input. Instead, it would seem that the influence of SI is to change the timing of an inferior olivary response that would have otherwise been generated at a longer latency. The fact that pharmacological interference of the SI to IO pathway or the absence of an SI response are both correlated with a lengthening of the CS response latency, is consistent with this idea. A modulatory role for SI is also consistent with data demonstrating that CS responses can be readily elicited in decorticate animals (Oscarsson, 1969; Rushmer et al., 1976; Bloedel and Ebner, 1984).

Although the focus of this study was on the relationship between SI and CS responses, the data in Figures 2 and 3 demonstrate that there is a correlation between spontaneous SI activity and SI response latency. We do not have enough data to determine the causality of this correlation, but we were able to determine that it was apparently responsible for the correlation be- tween spontaneous SI activity and CS response latency (Fig. 6D). The correlation between spontaneous SI activity and SI response latency, as well as the rising spontaneous activity readily observable for short-latency SI responses imply that the state of somatosensory cortex, as measured by spontaneous SI activity, might influence SI response latency. If so, then the state of somatosensory cortex can be said also to influence CS response latency. Further studies will be needed to clarify this relationship.

Our findings are also interesting in the context of what is known about the biophysical properties of the inferior olive. Studies have shown that the timing of repeated IO discharge in vitro is under the control of slow depolarization regulated by $\mathrm{Ca}^{2+}$ activated $\mathrm{K}^{+}$conductances (Llinas and Yarom, 1981a,b). When isolated in a slice, IO neurons discharge when the slow depolarization resulting from previous activity reaches the threshold for a subthreshold calcium-spiking mechanism. Our findings can be explained by assuming two distinct influences on IO neurons: one that, with a certain probability, sets the IO neuron into its slow depolarization phase, and a second SImediated input that, when superimposed on this slow depolarization, can cause the IO neuron to fire earlier than it otherwise would. The phase of slow depolarization could be induced by input from some other source (including a previous influence from SI), or it could reflect network level activity between coupled IO neurons (Llinas and Yarom, 1981a,b; Sasaki et al., 1989).

Whatever mechanism is responsible for setting the internal state of the IO, the proposed influence of SI is consistent with both the correlation in firing latencies of SI and climbing fibers, as well as the finding that climbing fiber discharges occur at their longest latencies when SI is not active. Without the SI influence, IO neurons simply respond at the end of their natural depolarization cycle as set by the first input.

\section{Influence of somatosensory cortex on cerebellum and its relevance to hypotheses of cerebellar function}

Like the cerebellum as a whole, our unusually detailed knowledge of the anatomical and physiological organization of climbing fiber projections from the inferior olive to the cerebellum has led directly to numerous speculations concerning the computational function of this pathway (Marr, 1969; Albus, 1971; Ito, 1982; Llinas and Welsh, 1993). In most of these speculations, the timing of climbing fiber discharge has played a critical role in the presumed function. For example, in the cerebellar learning hypotheses of Albus (1971) and Marr (1969), the precise timing of climbing fiber discharge was proposed to determine which of the 150,000 parallel fiber inputs on a particular Purkinje cell were modified in support of motor learning (Ito, 1982). In the motor timing hypothesis of Llinas, populations of climbing fibers discharging at the characteristic 7-12 Hz oscillatory frequency of the IO (Llinas and Yarom, 1986) are proposed to provide a universal timing signal for the control and coordination of movement (Llinas and Welsh, 1993).

While differing in the details, each of the previous hypotheses share in common the idea that the IO itself is responsible for controlling the critical timing of CS responses. In contrast, the data presented here suggest that the timing of IO activity is actually under the direct influence of the cerebral cortex and therefore could be more related to cerebral cortical events rather than cerebellar events. This assertion provides a very different context within which to consider what is known about the climbing fiber afferent system. For example, theoretical and experimental work in our laboratory on the oscillatory properties of the 
olfactory cortex have suggested that $7-12 \mathrm{~Hz}$ constitutes the fundamental frequency underlying computation in cerebral cortex as a whole (Bower, 1992; Fontanini et al., 2001). In this context, the 7-12 Hz resonate frequency of the IO (Llinas and Yarom, 1986) might simply anticipate the most likely temporal pattern of output from cerebral cortex, rather than provide by itself a clocking function for movement generation (Llinas and Welsh, 1993).

Viewed more generally, and based on the current data, we propose that at least one function of the IO and the climbing fiber system may be to provide the cerebellum specific information about the timing of cerebral cortical computation cycles. This idea fits quite well with the hypothesis we have been pursuing over a number of years, that these tactile regions of the cerebellum are directly involved in controlling the acquisition of tactile data on which computation in somatosensory cerebral cortex is dependent (Bower and Kassel, 1990; Bower, 1997a,b; Hartmann and Bower, 2001). By controlling the timing of climbing fiber discharges, the cerebral cortex is provided a mechanism for influencing directly the way that the cerebellum is controlling the data on which somatosensory cortex depends. Experimental and modeling studies currently underway are intended to better understand the nature of that influence mediated through the climbing fiber on the dendrite of the Purkinje cell.

\section{REFERENCES}

Albus JS (1971) A theory of cerebellar function. Math Biosci 10:25-61. Allen GI, Azzena GB, Ohno T (1974) Cerebellar Purkyne cell responses to inputs from sensorimotor cortex. Exp Brain Res 20:239-254.

Atkins MJ, Apps R (1997) Somatotopical organisation within the climbing fibre projection to the paramedian lobule and copula pyramidis of the rat cerebellum. J Comp Neurol 389:249-263.

Bloedel JR, Ebner TJ (1984) Rhythmic discharge of climbing fibre afferents in response to natural peripheral stimuli in the cat. J Physiol (Lond) 352:129-146.

Bower JM (1992) Relations between the dynamical properties of single cells and their networks in piriform (olfactory) cortex. In: Single neuron computation (McKenna T, Davis J, Zornetzer SF, eds), pp 437-462. San Diego: Academic.

Bower JM (1997a) Is the cerebellum sensory for motor's sake, or motor for sensory's sake: the view from the whiskers of a rat? Prog Brain Res 114:483-516.

Bower JM (1997b) The cerebellum and the control of sensory data acquisition. In: The cerebellum and cognition (Schmahmann J, ed), pp 489-513. San Diego: Academic.

Bower JM, Kassel J (1990) Variability in tactile projection patterns to cerebellar folia crus IIA of the Norway rat. J Comp Neurol 302: 768-778.

Bower JM, Woolston DC (1983) Congruence of spatial organization of tactile projections to granule cell and Purkinje cell layers of cerebellar hemispheres of the albino rat: vertical organization of cerebellar cortex. J Neurophysiol 49:745-766.

Bower JM, Beermann DH, Gibson JM, Shambes GM, Welker W (1981) Principles of organization of a cerebro-cerebellar circuit. Micromapping the projections from cerebral (SI) to cerebellar (granule cell layer) tactile areas of rats. Brain Behav Evol 18:1-18.

Brown IE, Bower JM (2000) Correlations between S1 field potentials and cerebellar complex spikes in response to peripheral tactile stimuli. Soc Neurosci Abstr 26:1985.

Brown IE, Bower JM (2001) Congruence of mossy fiber and climbing fiber Tactile projections in the lateral hemispheres of the rat cerebellum. J Comp Neurol 429:59-70.

Bruce LL, McHaffie JG, Stein BE (1987) The organization of trigeminotectal and trigeminothalamic neurons in rodents: a double-labeling study with fluorescent dyes. J Comp Neurol 262:315-330.

Fontanini A, Vanier MC, Moore LE, Bower JM (2001) Membrane potential oscillations in piriform cortex pyramidal cells: in vivo intracellular and local field potential recordings. Soc Neurosci Abstr 27:726.5.

Fukushima T, Kerr FW (1979) Organization of trigeminothalamic tracts and other thalamic afferent systems of the brainstem in the rat: presence of gelatinosa neurons with thalamic connections. J Comp Neurol 183:169-184.
Gellman R, Houk JC, Gibson AR (1983) Somatosensory properties of the inferior olive of the Cat. J Comp Neurol 215:228-243.

Gellman R, Gibson AR, Houk JC (1985) Inferior olivary neurons in the awake cat: detection of contact and passive body displacement. J Neurophysiol 54:40-60.

Hall RD, Lindholm EP (1974) Organization of motor and somatosensory neocortex in the albino rat. Brain Res 66:22-38.

Hartmann MJ, Bower JM (2001) Tactile responses in the granule cell layer of cerebellar folium crus IIa of freely behaving rats. J Neurosci 21:3549-3563.

Horn KM, Hamm TM, Gibson AR (1998) Red nucleus stimulation inhibits within the inferior olive. J Neurophysiol 80:3127-3136.

Houk JC, Wise SP (1995) Distributed modular architectures linking basal ganglia, cerebellum, and cerebral-cortex: their role in planning and controlling action. Cereb Cortex 5:95-110.

Houk JC, Buckingham JT, Barto AG (1996) Models of the cerebellum and motor learning. Behav Brain Sci 19:368-383.

Huerta MF, Frankfurter A, Harting JK (1983) Studies of the principal sensory and spinal trigeminal nuclei of the rat: projections to the superior colliculus, inferior olive, and cerebellum. J Comp Neurol 220:147-167.

Ito M (1982) Experimental verification of Marr-Albus' plasticity assumption for the cerebellum. Acta Biol 33:189-199.

Kawato M, Gomi H (1992) A computational model of four regions of the cerebellum based on feedback-error learning. Biol Cybern 68:95-103.

Koralek KA, Jensen KF, Killackey HP (1988) Evidence for two complementary patterns of thalamic input to the rat somatosensory cortex. Brain Res 463:346-351.

Leergaard TB, Lyngstad KA, Thompson JH, Taeymans S, Vos BP, De Schutter E, Bower JM, Bjaalie JG (2000) Rat somatosensory cerebropontocerebellar pathways: spatial relationships of the somatotopic map of the primary somatosensory cortex are preserved in a three-dimensional clustered pontine map. J Comp Neurol 422:246-266.

Leichnetz GR, Spencer RF, Smith DJ (1984) Cortical projections to nuclei adjacent to the oculomotor complex in the medial dienmesencephalic tegmentum in the monkey. J Comp Neurol 228:359-387.

Llinas R, Welsh JP (1993) On the cerebellum and motor learning. Curr Opin Neurobiol 3:958-965.

Llinas R, Yarom Y (1981a) Electrophysiology of mammalian inferior olivary neurones in vitro. Different types of voltage-dependent ionic conductances. J Physiol (Lond) 315:549-567.

Llinas R, Yarom Y (1981b) Properties and distribution of ionic conductances generating electroresponsiveness of mammalian inferior olivary neurones in vitro. J Physiol (Lond) 315:569-584.

Llinas R, Yarom Y (1986) Oscillatory properties of guinea-pig inferior olivary neurones and their pharmacological modulation: an in vitro study. J Physiol (Lond) 376:163-182.

Malpeli JG (1999) Reversible inactivation of subcortical sites by drug injection. J Neurosci Methods 86:119-128.

Marr D (1969) A theory for cerebellar cortex. J Physiol (Lond) 202: $437-470$.

McCurdy ML, Gibson AR, Houk JC (1992) Spatial overlap of rubrospinal and corticospinal terminals with input to the inferior olive. NeuroImage 1:23-41.

Miles TS, Wiesendanger M (1975) Organization of climbing fibre projections to the cerebellar cortex from trigeminal cutaneous afferents and from the SI face area of the cerebral cortex in the cat. J Physiol (Lond) 245:409-424.

Miller S, Nezlina N, Oscarsson O (1969) Projection and convergence patterns in climbing fibre paths to cerebellar anterior lobe activated from cerebral cortex and spinal cord. Brain Res 14:230-233.

Morissette J, Bower JM (1996) Contribution of somatosensory cortex to responses in the rat cerebellar granule cell layer following peripheral tactile stimulation. Exp Brain Res 109:240-250.

Oscarsson O (1969) Termination and functional organization of the dorsal spino-olivocerebellar path. J Physiol (Lond) 200:129-149.

Palay SL, Chan-Palay V (1974) Cerebellar cortex: cytology and organization. Berlin: Springer.

Robertson LT (1987) Organization of climbing fiber representation in the anterior lobe. New York: Wiley.

Rowe MJ (1977) Cerebral cortical areas associated with the activation of climbing fibre input to cerebellar Purkinje cells. Arch Ital Biol 115:79-93.

Rushmer DS, Roberts WJ, Augter GK (1976) Climbing fiber responses of cerebellar Purkinje cells to passive movement of the cat forepaw. Brain Res 106:1-20.

Saint-Cyr JA (1987) Anatomical organization of cortico-mesencephaloolivary pathways in the cat as demonstrated by axonal transport techniques. J Comp Neurol 257:39-59. 
Sasaki K, Bower JM, Llinás R (1989) Multiple Purkinje cell recording in rodent cerebellar cortex. Eur J Neurosci 1:572-586.

Sousa-Pinto A, Brodal A (1969) Demonstration of a somatotopical pattern in the cortico-olivary projection in the cat. An experimentalanatomical study. Exp Brain Res 8:364-386.

Swenson RS, Castro AJ (1983a) The afferent connections of the inferior olivary complex in rats. an anterograde study using autoradiographic and axonal degeneration techniques. Neuroscience 8: $259-275$.

Swenson RS, Castro AJ (1983b) The afferent connections of the inferior olivary complex in rats: a study using the retrograde transport of horseradish peroxidase. Am J Anat 166:329-341.

Thach WT, Goodkin HP, Keating JG (1992) The cerebellum and the adaptive coordination of movement. Annu Rev Neurosci 15:403-442.

Waite PM (1984) Rearrangement of neuronal responses in the trigeminal system of the rat following peripheral nerve section. J Physiol (Lond) 352:425-445.

Watson CRR, Switzer RCI (1978) Trigeminal projections to cerebellar tactile areas in the rat-origin mainly from $\mathrm{N}$. interpolaris and $\mathrm{N}$. principalis. Neurosci Lett 10:77-82.

Weiss C, Houk JC, Gibson AR (1990) Inhibition of sensory responses of cat inferior olive neurons produced by stimulation of red nucleus. J Neurophysiol 64:1170-1185.

Williams MN, Zahm DS, Jacquin MF (1994) Differential foci and synaptic organization of the principal and spinal trigeminal projections to the thalamus in the rat. Eur J Neurosci 6:429-453. 